\title{
Genetic disorders of nuclear receptors
}

\author{
John C. Achermann, ${ }^{1}$ John Schwabe, ${ }^{2}$ Louise Fairall, ${ }^{2}$ and Krishna Chatterjee ${ }^{3}$ \\ ${ }^{1}$ Cenetics and Genomic Medicine, UCL Great Ormond Street Institute of Child Health, University College London, London, United Kingdom. ² Leicester Institute of Structural and Chemical Biology, \\ Department of Molecular and Cell Biology, University of Leicester, Leicester, United Kingdom. ${ }^{3}$ Wellcome Trust-MRC Institute of Metabolic Science, University of Cambridge, Cambridge, United Kingdom.
}

\begin{abstract}
Following the first isolation of nuclear receptor (NR) genes, genetic disorders caused by NR gene mutations were initially discovered by a candidate gene approach based on their known roles in endocrine pathways and physiologic processes. Subsequently, the identification of disorders has been informed by phenotypes associated with gene disruption in animal models or by genetic linkage studies. More recently, whole exome sequencing has associated pathogenic genetic variants with unexpected, often multisystem, human phenotypes. To date, defects in $\mathbf{2 0}$ of $\mathbf{4 8}$ human NR genes have been associated with human disorders, with different mutations mediating phenotypes of varying severity or several distinct conditions being associated with different changes in the same gene. Studies of individuals with deleterious genetic variants can elucidate novel roles of human NRs, validating them as targets for drug development or providing new insights into structure-function relationships. Importantly, human genetic discoveries enable definitive disease diagnosis and can provide opportunities to therapeutically manage affected individuals. Here we review germline changes in human NR genes associated with "monogenic" conditions, including a discussion of the structural basis of mutations that cause distinctive changes in NR function and the molecular mechanisms mediating pathogenesis.
\end{abstract}

\section{Introduction}

It has been almost 30 years since the first human nuclear receptor (NR) disorders were characterized at the molecular level (Figure 1). Since then, disorders associated with genetic defects in 20 of the 48 known human NRs have been identified (Figure 1 and Tables 1 and 2). In this Review we provide a brief overview of the range of human NR-associated diseases reported to date and highlight some of the key pathogenic mechanisms involved (Figure 2A). Our focus is on well-established monogenic germline disorders. We will not cover the role of somatic NR variations or fusion genes in cancer, nor associations found in GWAS.

\section{Thyroid hormone receptor $\alpha$ and $\beta$}

Thyroid hormone (TH) regulates physiologic processes (e.g., skeletal growth, maturation of the CNS, heart rate and contractility, energy expenditure) via receptors (thyroid receptor $\alpha 1$ [TR $\alpha 1$, TR $\beta 1$, and TR $\beta 2$ ) encoded by separate genes (THRA/NR1A1, $T H B R / N R 1 A 2)$, with differing tissue distributions: TR $\alpha 1$ is highly expressed in the CNS, myocardium, gastrointestinal tract, and skeletal muscle; TR $\beta 1$ is the predominant isoform in liver and kidney; TR $\beta 2$ expression is restricted principally to the hypothalamus, pituitary, retina, and inner ear. Such divergence of receptor subtype expression likely mediates distinctive phenotypes associated with defective THRB or THRA.

Resistance to TH $\beta$ (RTH $\beta$ ), usually dominantly inherited, is recognized by a characteristic biochemical signature of elevated circulating $\mathrm{TH}$ and non-suppressed thyroid-stimulating hormone levels, reflecting central (hypothalamic-pituitary) resistance to $\mathrm{TH}$ action, together with variable resistance in peripheral tissues.

Conflict of interest: The authors have declared that no conflict of interest exists. Reference information: / Clin Invest. 2017;127(4):1181-1192.

https://doi.org/10.1172/JCl88892.
Approximately 160 different heterozygous THRB mutations, localizing to the ligand-binding domain (LBD) and involving both TR $\beta 2$ and TR $\beta 1$ isoforms, have been identified in the disorder (1).

Affected individuals may have nonspecific symptoms or a goiter, prompting thyroid function tests that suggest the diagnosis and are deemed to have generalized RTH (GRTH). In approximately $15 \%$ of cases, the same biochemical picture can be associated with thyrotoxic features (e.g., weight loss, tremor, anxiety, tachycardia in adults; failure to thrive and hyperkinetic behavior in children); a disproportionate resistance to TH in TR $\beta$-expressing hypothalamus and pituitary (PRTH), with relative retention of hormone sensitivity in TR $\alpha$-expressing peripheral tissues, may account for this phenotype. GRTH and PRTH phenotypes can be associated with the same TR $\beta$ mutation and may even coexist within a single family. Other recognized features of the disorder include attention-deficit hyperactivity disorder in childhood and dyslipidemia and reduced bone mineral density in adults (1).

Consonant with their location, most TR $\beta$ mutations impair hormone binding or (rarely) coactivator recruitment and inhibit action of their wild-type counterparts in a dominant-negative manner (Figure 2B). Receptor functional regions (such as DNA binding, dimerization, and corepressor binding) are devoid of naturally occurring TR $\beta$ mutations, with RTH $\beta$ variants clustering within hotspots within the LBD (1). Homozygous THRB deletion mediated RTH $\beta$ in the first two recorded siblings with this disorder, who also had audiovisual abnormalities (2). Biallelic missense mutations were present in five other recessively inherited cases (3). In roughly $15 \%$ of people with biochemical features of RTH $\beta$, no THRB defect can be identified; in such situations, alterations in co-regulators or other factors mediating $\mathrm{TH}$ action have been postulated (1). Triiodothyroacetic acid treatment, a centrally acting $\mathrm{TH}$ analogue that lowers $\mathrm{TH}$ levels, can control thyrotoxic features of the disorder. 
Table 1. Pathogenic variants in classic ligand-dependent NRs associated with human genetic disorders

\begin{tabular}{|c|c|c|c|c|c|c|c|c|c|}
\hline Receptor & Original name & Official name & HGNC gene & Ligand & OMIM & First report ${ }^{A}$ & $\begin{array}{c}\text { Number of } \\
\text { cases/families }^{B}\end{array}$ & Inherited & Condition \\
\hline $\operatorname{TR} \alpha$ & $\begin{array}{l}\text { Thyroid hormone } \\
\text { receptor- } \alpha\end{array}$ & NR1A1 & THRA & THs & 614450 & 2012 & 50 & $A D$ & $\mathrm{RTH} \alpha$ \\
\hline \multirow[t]{2}{*}{$\operatorname{TR} \beta$} & $\begin{array}{l}\text { Thyroid hormone } \\
\text { receptor- } \beta\end{array}$ & NR1A2 & THRB & THs & 188570 & $1989^{c}$ & $>200$ & $A D$ & RTH (dominant) \\
\hline & & & & & 274300 & 1992 & 5 & Autosomal recessive & RTH (recessive) \\
\hline VDR & Vitamin D receptor & NR111 & VDR & $\begin{array}{c}\text { Vitamin } \mathrm{D} \\
\text { 1,25-dihydroxyvitamin } \mathrm{D}_{3}\end{array}$ & 277440 & $1988^{\circ}$ & 100 to 200 & $\begin{array}{l}\text { Autosomal } \\
\text { recessive }\end{array}$ & $\begin{array}{l}\text { Vitamin D-resistant } \\
\text { rickets type IIA }\end{array}$ \\
\hline GR & $\begin{array}{l}\text { Glucocorticoid } \\
\text { receptor }\end{array}$ & $N R 3 C 1$ & NR3C1 & Cortisol & 615962 & $1991^{\mathrm{E}}$ & 10 to 50 & $\begin{array}{c}\text { Autosomal } \\
\text { dominant, } \\
\text { autosomal recessive }\end{array}$ & $\begin{array}{l}\text { Glucocorticoid } \\
\text { resistance }\end{array}$ \\
\hline \multirow[t]{2}{*}{ MR } & $\begin{array}{l}\text { Mineralocorticoid } \\
\text { receptor }\end{array}$ & NR3C2 & $N R 3 C 2$ & Aldosterone & 177735 & $1998^{F}$ & 50 to 100 & Autosomal dominant & PHAI \\
\hline & & & & & 605115 & 2001 & 1 & $\begin{array}{c}\text { Autosomal } \\
\text { dominant }\end{array}$ & $\begin{array}{c}\text { Hypertension with } \\
\text { exacerbation in } \\
\text { pregnancy }\end{array}$ \\
\hline $\mathrm{ER} \alpha$ & $\begin{array}{c}\text { Estrogen receptor } \\
\alpha\end{array}$ & NR3A1 & ESR1 & Estradiol & 615363 & 1994 & 3 & $\begin{array}{l}\text { Autosomal } \\
\text { recessive }\end{array}$ & Estrogen resistance \\
\hline \multirow[t]{4}{*}{ AR } & Androgen receptor & NR3C4 & $A R$ & Testosterone & 300068 & $1989^{\complement}$ & $>200$ & XLR & AIS \\
\hline & & & & & 312300 & 1991 & $>200$ & XLR & $\begin{array}{l}\text { Partial androgen } \\
\text { insensitivity }\end{array}$ \\
\hline & & & & & n.a. & 1994 & 50 to 100 & XLR & $\begin{array}{l}\text { Mild androgen } \\
\text { insensitivity } \\
\text { (infertility) }\end{array}$ \\
\hline & & & & & 313200 & 1994 & $>200$ & XLR & SBMA \\
\hline
\end{tabular}

${ }^{A}$ Year in which point mutations in the causative gene were first published. In some situations, described in footnotes D- $\mathrm{C}$, the clinical disorder or

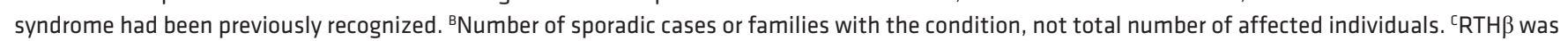


studied further in relation to possible GR insensitivity throughout the 1980s. FPHA in infancy was first reported in 1958. Decreased aldosterone binding to patient cells, which suggested an MR defect, was documented in 1985. 'AIS was first reported as "testicular feminization syndrome" in 1953. In the 1960 s and 1970s it was recognized as an X-linked disorder thought to be due to androgen resistance. In the 1980 s reduced androgen binding to patient fibroblasts was shown in a subset of individuals with AIS. HGNC, HUGO Gene Nomenclature Committee; OMIM, Online Mendelian Inheritance in Man; XLR, X-linked recessive.

RTH $\alpha$, characterized by features of hypothyroidism in selected tissues, eluded discovery probably because thyroid function tests are near-normal in the disorder. Most cases have been identified in childhood, with features including disproportionate (lower segment) growth retardation, macrocephaly, dysmorphic features, constipation, dyspraxia, and intellectual deficit. Biochemical abnormalities include low/low-normal thyroxine (T4) and high/high-normal triiodothyronine (T3) computing to a low $\mathrm{T} 4 / \mathrm{T} 3$ ratio, variably reduced reverse $\mathrm{T} 3$, elevated muscle creatine kinase levels, and anemia $(4,5)$.

Heterozygous THRA mutations disrupt TR $\alpha 1$ function either markedly or partially and inhibit wild-type receptor action in a dominant-negative manner via a mechanism involving enhanced corepressor recruitment and target gene repression (Figure 2B, Figure $3 \mathrm{~A}$, and ref. 5). Some THRA defects also involve the carboxyterminally divergent, non-hormone-binding $\mathrm{TR} \alpha 2$ isoform, with no discernible added clinical phenotype or gain or loss of function attributable to the TR $\alpha 2$ variant (6). Consonant with resemblance of the RTH $\alpha$ phenotype to some features seen in conventional hypothyroidism, T4 therapy reverses metabolic abnormalities and improves growth, constipation, dyspraxia, and well-being.

\section{Vitamin D receptor}

The principal role of the vitamin $\mathrm{D}$ receptor (VDR, encoded by NR1I1) is in the regulation of calcium and phosphate metabolism with actions in the gastrointestinal tract, kidney, and bone. Hypocalcemia and associated symptoms (skeletal and respiratory muscle weakness, seizures) in the early neonatal period or infancy due to lack of VDR-dependent intestinal calcium absorption dominates the phenotype of autosomal recessive hereditary vitamin D-resistant rickets (HVDRR, also known as vitamin D-dependent rickets type II). Rickets manifests with bone pain, growth restriction, and fractures. Low circulating calcium and phosphate levels and raised alkaline phosphatase are associated with normal serum 25-hydroxy but very elevated 1,25 dihydroxyvitamin D3 (calcitriol) levels, secondary hyperparathyroidism, and elevated parathyroid hormone levels. Alopecia (patchy or total) affecting both scalp and body is a distinctive, non-osseous feature of the disorder.

Approximately 100 cases of HVDRR harboring approximately 45 different homozygous or compound heterozygous VDR mutations have been recorded: frameshift, premature-stop, and DNA-binding domain (DBD) mutations lead to complete loss of function. Additionally, approximately $20 \mathrm{LBD}$ variants exhibit 


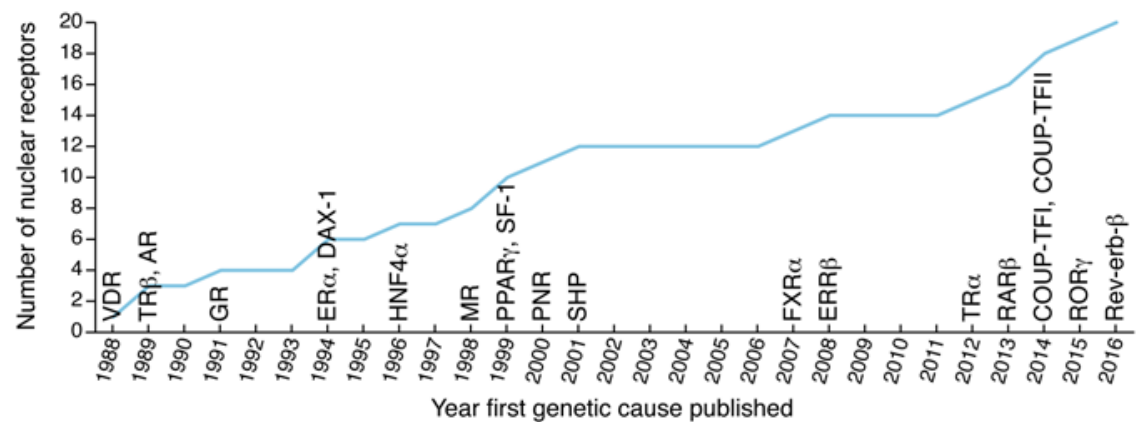

Figure 1. A timeline of identification of defects in human NR genes. The year of the first publication describing a monogenic disorder associated with each NR is shown along the $x$ axis. The cumulative number of human NRs associated with a disorder are shown by the $y$ axis. reduced ligand binding, failure to heterodimerize with retinoid $\mathrm{X}$ receptor (RXR), or selective loss of coactivator recruitment (Figure 3B); a single HVDRR case lacking a VDR mutation has also been described (7). In one family, a missense VDR mutation ( $p$. Glu420Ala), which abolished coactivator binding and exhibited dominant-negative activity, mediated HVDRR in the heterozygous state (8). Patients with HVDRR require oral or intravenous calcium therapy; high-dose vitamin D or calcitriol treatment can overcome the receptor defect in LBD mutation cases (7), raising the possibility of structure-guided design of synthetic analogues for treatment of a subset of HVDRR (9).

Interestingly, alopecia occurs in patients with VDR mutations that lead to loss of receptor expression, DNA binding, or dimerization, but it is not a feature in cases with ligand binding or coactivator recruitment defects. This abnormality is unresponsive to calcitriol therapy, leading to the hypothesis that inhibition of target genes by unliganded, wild-type VDR maintains normal cycling of hair follicles, with loss of such repression mediating hair loss (Figure $2 \mathrm{C}$ ). Supporting this notion, mutations in hairless, a known component of NR repression complexes, also cause an alopecia syndrome (atrichia with papules) (10).

\section{Glucocorticoid receptor $\alpha$}

Disruption of glucocorticoid receptor $\alpha$ (GR $\alpha$, encoded by NR3C1) is associated with familial glucocorticoid resistance (FGR, also known as generalized glucocorticoid resistance or Chrousos syndrome) $(11,12)$. This can be dominantly or recessively inherited, with a range of features depending on the severity of the defect or underlying molecular mechanism. Individuals with FGR often present with fatigue, but other signs of glucocorticoid insufficiency are rare. Because of reduced central feedback, adrenocorticotropic hormone (ACTH) is elevated, increasing cortisol and partly compensating for glucocorticoid resistance. One consequence of elevated ACTH is an increase in adrenal mineralocorticoid and androgen production. Consequently, clinical and biochemical features of FGR can include hypertension, hypokalemia, and metabolic alkalosis as well as hirsutism, acne, male pattern baldness, oligomenorrhea, and infertility.

Most pathogenic missense variants in GR $\alpha$ are located in the LBD and affect glucocorticoid binding or transactivation. Patients or carriers with heterozygous changes tend to have a milder phenotype, although dominant-negative LBD variants have been reported (p.Ile559Asn, Ile747Met) $(13,14)$. LBD mutants often show variably reduced ligand binding affinity as well as delayed nuclear translocation and altered interactions with coactivators (e.g., p160) (14). Clinical and biochemical features in individuals with homozygous mutations in NR3C1 are usually more severe. No familial activating mutations in GR $\alpha$ have been reported, but a heterozygous variant (p.Asp410His) was reported in a woman with features of tissue-selective glucocorticoid hypersensitivity (e.g., visceral obesity, dyslipidemia, type 2 diabetes [T2D], hypertension) (15). This mutant receptor increased transactivation of glucocorticoid-responsive genes.

\section{Mineralocorticoid receptor}

The mineralocorticoid receptor ( $\mathrm{MR}$, encoded by $N R 3 C 2)$ plays a key role in renal sodium retention and cardiovascular endocrinology. Pathogenic loss-of-function variants in this receptor are associated with a renal form of mineralocorticoid resistance known as autosomal-dominant (or sporadic) pseudohypoaldosteronism type 1 (PHA I) $(16,17)$. Children typically present in early infancy with dehydration and failure to thrive and have hyponatremia, hyperkalemia, and elevated aldosterone levels and plasma renin activity (PRA). Some infants with elevated aldosterone and PRA are asymptomatic. Sodium supplementation is usually required, but the condition improves in childhood. In contrast, the autosomal recessive form of PHA I, due to defects in the amiloridesensitive epithelial sodium channel, is a more severe systemic condition that does not remit with age.

Pathogenic MR mutations include nonsense, frameshift, splice and missense mutations, with a potential hotspot at c.2839C $>\mathrm{T}$ (p.Arg947*). Missense mutations often affect key amino acids in the LBD and impair aldosterone binding and aldosteronedependent transactivation $(16,18)$. Nuclear localization can sometimes be affected and different variants may have differential effects on MR-target genes (e.g., SGK1, NDRG2, GILZ, SCNN1A) $(18,19)$.

A gain-of-function MR variant was reported in 2000, in one family with early-onset hypertension (onset before the age of 20) (20). Females also exhibited marked hypertension during pregnancy. The heterozygous p.Ser810Leu variant identified in affected family members showed mild constitutive activity together with inappropriate responsiveness to progesterone. The leucine substitution at position 810 increases van der Waals interactions and lessens hydrogen bonding with steroid side groups, thereby enabling progesterone to bind and activate mutant MR (Figure 3C). Although this germline mutation is rare, it exemplifies how genetic variants in NRs can potentially alter ligand specificity; such altered ligand specificity is well recognized with somatic ER $\alpha$ variants in breast cancer or androgen receptor (AR) mutations in prostate cancer. 
A

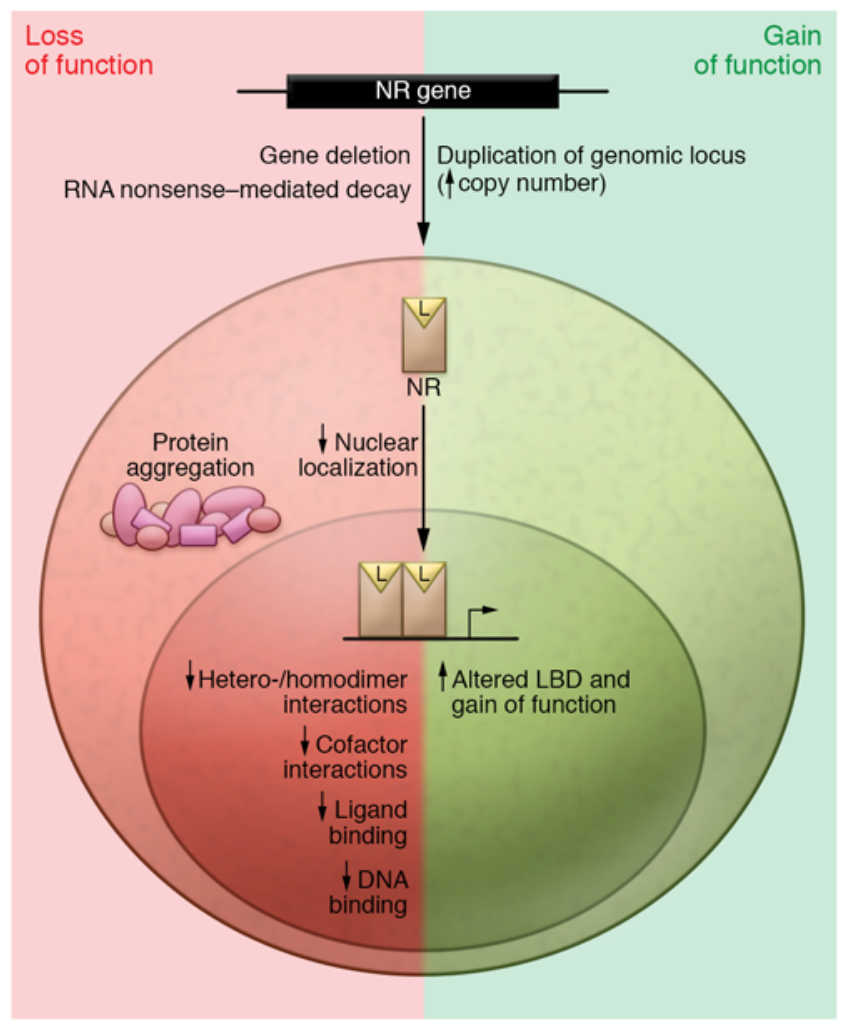

B

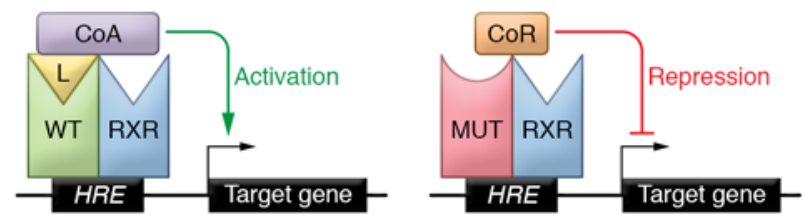

C
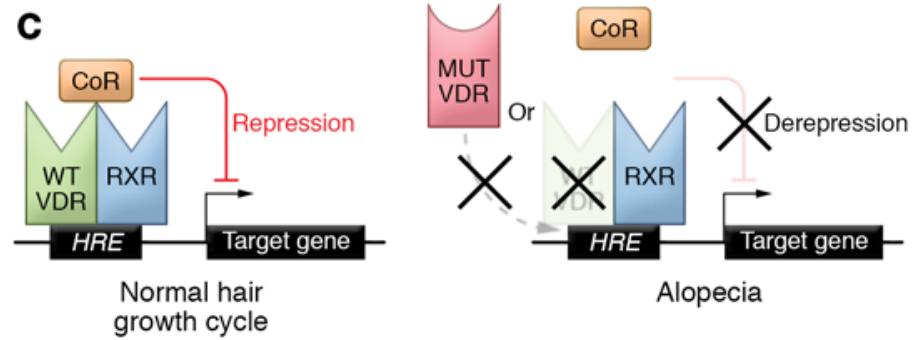

Alopecia

Figure 2. Molecular mechanisms of disrupted NR action. (A) Mechanisms whereby NR gene and protein changes can alter function. Gene deletion or mutations causing mRNA instability or impairing key cellular functions can cause loss of function (left). Gain of receptor function may occur due to duplication of an NR genomic locus (e.g., NROB1) or LBD mutation (right). (B) In several disorders heterozygous receptor mutants (e.g., TR $\beta$, TR $\alpha$, PPAR $\gamma$, VDR) inhibit the action of their wild-type counterparts in a dominant-negative manner. In contrast to the wild-type receptor, either defective binding of ligand (L) or recruitment of coactivator (CoA) by a mutant (MUT) receptor impairs its dissociation of corepressor (CoR), mediating constitutive repression of target gene expression. HRE, hormone response element. (C) Alopecia is not a universal feature of hereditary vitamin D resistance. It is associated with VDR mutations that disrupt DNA binding, that cause loss of heterodimerization with RXR, or that cause loss of receptor expression, but not with variants exhibiting impaired ligand binding affinity or coactivator recruitment. Repression of target genes by unliganded wild-type receptor maintains a normal hair growth cycle, and the loss of such inhibition that accompanies a subset of VDR mutants (right) is thought to mediate this variable phenotype.

\section{Estrogen receptor $\alpha$}

Estrogen receptor $\alpha(\mathrm{ER} \alpha$, encoded by ESR1 [also referred to as NR3A1]) is one of the best-studied NRs in human biology. To date, only three genomic pathogenic variants associated with a clear phenotype have been reported; however, these cases do provide important insight into the role of ER $\alpha$ in human development and health.

The first report of a pathogenic ESR1 variant in 1994 involved a 28 -year-old man who presented with tall stature $(204 \mathrm{~cm})$, prolonged linear growth, delayed epiphyseal fusion, and reduced bone mineral density ( $z$ score -3.1$)(21,22)$. He had normal puberty, but had elevated levels of follicle-stimulating hormone and luteinizing hormone and reduced sperm viability. He also had impaired glucose tolerance, hyperinsulinemia, and an abnormal lipid profile with evidence of early coronary atherosclerosis, although his BMI was elevated $\left(30.5 \mathrm{~kg} / \mathrm{m}^{2}\right)$. Genetic analysis revealed a homozygous stop gain variant (p.Arg157*). He had mildly elevated serum estradiol and resistance to estrogen treatment.

In 2013, the first female with estrogen resistance was reported (23). This 18-year-old woman presented with absent breast development, primary amenorrhea, and abdominal pain due to hemorrhagic ovarian cysts. She had a small uterus with no endo- metrium, but did have evidence of androgenization. Her bone age was markedly delayed ( $>4$ years), she did not have a pubertal growth spurt, and her bone density was reduced ( $z$ score -2.4$)$ with elevated markers of osteoblastic activity. Her estradiol was very elevated (10-fold above normal) with elevated inhibin A and mildly raised gonadotropins, and she was resistant to estrogen treatment. Analysis of ESR1 revealed a homozygous missense variant (p.Gln375His) in the LBD that impaired estrogen responsiveness in cell-based assays. More recently, a description was published of the first known family with estrogen resistance (p.Arg394His) (24).

These reports provide important information about the role of ER $\alpha$ in humans. As expected, ER $\alpha$ mediates the main effects of estrogen on bone growth and mineralization, as well as breast and uterine development in females. As in ER-knockout mice, gonadotropin concentrations are higher in males, possibly because very high estradiol and inhibin A levels in females partly mediate central feedback. Finally, the woman described above had no evidence of hyperinsulinemia or glucose intolerance, but she had a low BMI $(16.6 \mathrm{~kg} / \mathrm{m} 2)$ and body fat (28\%). Long-term monitoring is needed to see whether metabolic abnormalities develop, although the difference in BMI between the two individuals may be a factor influencing insulin sensitivity. 
A TR
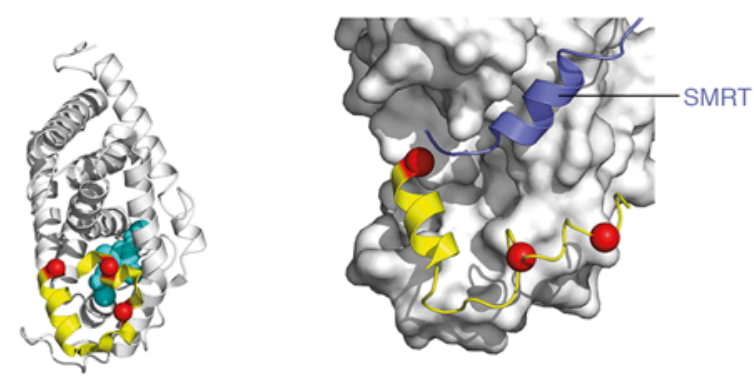

B VDR
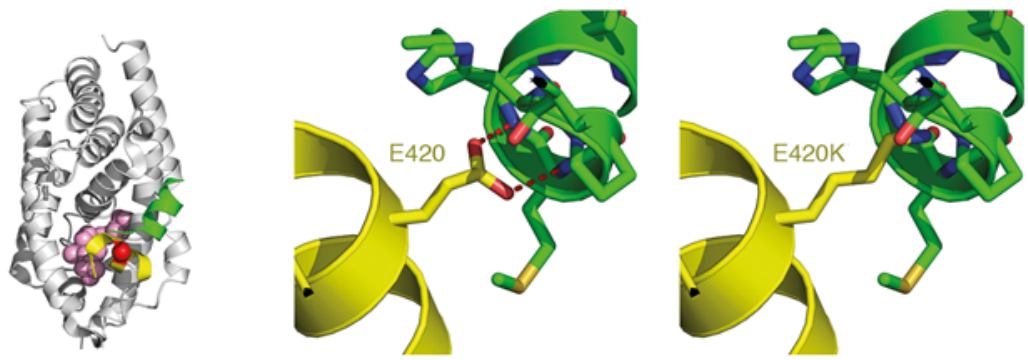

C MR
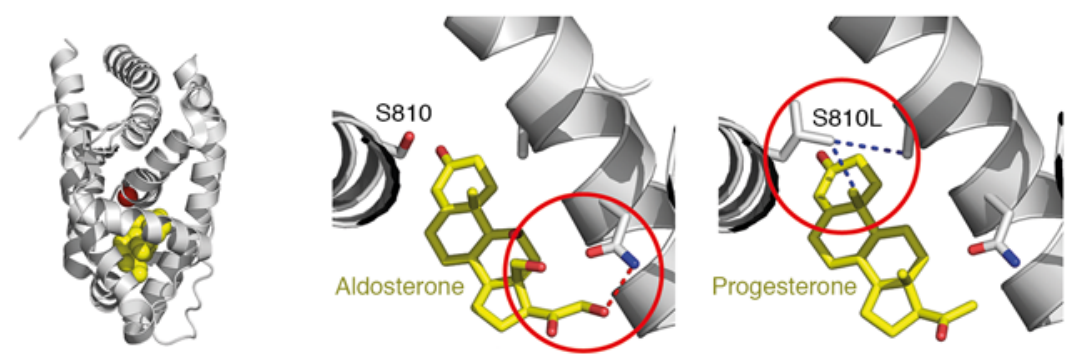

D

SF-1/NR5A1
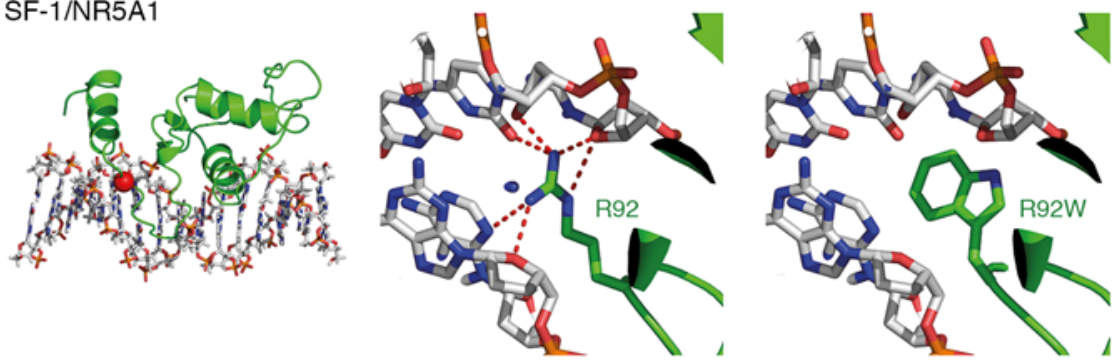

Figure 3. Structural modeling of NR mutations.(A) Modeling (PDB 2H77 TR $\alpha$, PDB 1KKQ SMRT) shows that mutation of residues (red spheres) in the carboxyterminal region of TR $\alpha$, which prematurely truncate helix 11 or 12 (left), facilitate its ability to accommodate corepressor (SMRT, blue) within a groove at the receptor surface (right). (B) Modeling (PDB 1RK3, VDR bound to DRIP 205 coactivator) shows that a glutamic acid residue (left; red sphere) hydrogen bonds with the peptide backbone of coactivator (middle; green). Mutation to lysine abolishes this interaction (right).(C) Modeling (PDB 5HCV MR, PDB 5L7E S810L mutant MR) shows that wild-type receptor, with serine at position 810, accommodates aldosterone via hydrogen bonding with steroid (middle; red dotted line), whereas mutant MR with a leucine substitution accommodates progesterone via van der Waals interaction with steroid (right; blue dotted line). (D) Modeling (PDB 2FF0) shows SF-1/NR5A1 bound to DNA. R92 makes an extensive hydrogen bond network in the minor groove to support monomeric binding. This interaction is disrupted by the R92W mutation due to the presence of an indole side group.

quent investigations show an absent uterus, 46,XY karyotype, and elevated testosterone concentrations. Breast development usually occurs in adolescence due to the aromatization of androgens to estrogens, but androgen-dependent pubic hair is often absent or sparse. Occasionally the diagnosis is made when testes are found during hernia repair in childhood or with karyotype analysis for another indication. As with most conditions, a spectrum of phenotypes can occur. Partial AIS (PAIS) typically presents with atypical genitalia or hypospadias in the newborn period, and gynecomastia is a common feature at adolescence in boys with this condition (27). Mild AIS (MAIS) has also been reported in men with oligospermic infertility (28).

More than 800 different pathogenic variants in the $A R$ have been reported. These changes include stop-gain, frameshift, and missense variants that are distributed throughout the gene and have been reviewed extensively elsewhere $(26,29,30)$. Missense variants tend to affect important amino acids involved in DNA binding or ligand interactions, but many different residues can be affected. Although some mutations associate more with complete or partial phenotypes, there can be overlap between the type and location of the change, its activity in in vitro assays, and the degree of androgen insensitivity in affected individuals. Missensemutationsinthehydrophobicligandbinding pocket of the LBD usually cause CAIS (26), while missense mutations in the large aminoterminal activation function domain (AF-1) usually cause PAIS or MAIS. Of note, a subset of individuals thought to have AIS do not have variants in the $A R$ gene, even though cultured genital fibroblasts show androgen resistance in vitro (e.g., reduced dihydrotestosterone-induced apolipoprotein D expression) (31). Disruption of ARdependent cofactors or post-receptor signaling mechanisms have been proposed as the cause (AIS type II) (31).

The AR is unusual in that it has a variable number of polyglutamine and polyglycine repeats in the aminoterminal region of the receptor. Expansion of the polyglutamine tract (to 38-65 CAG trinucleotide repeats) is

\section{AR}

Disruption of the AR (encoded by NR3C4) results in androgen insensitivity syndrome (AIS) (25). This X-linked condition was first reported in 1953 and has historically been called "testicular feminization syndrome" (26). Women with complete AIS (CAIS) typically present during late adolescence with primary amenorrhea. Subse- associated with $\mathrm{X}$-linked spinal and bulbar muscular atrophy (SBMA, also known as Kennedy disease) (32). This condition results from ARpolyglutamine toxicity; the mutant protein misfolds and aggregates in spinal cord motor neurons and muscle cells. SBMA can sometimes be associated with reduced androgen action, gynecomastia, low sperm count, and testicular atrophy (33). 
Table 2. Pathogenic variants in orphan or non-classic NRs associated with human genetic disorders

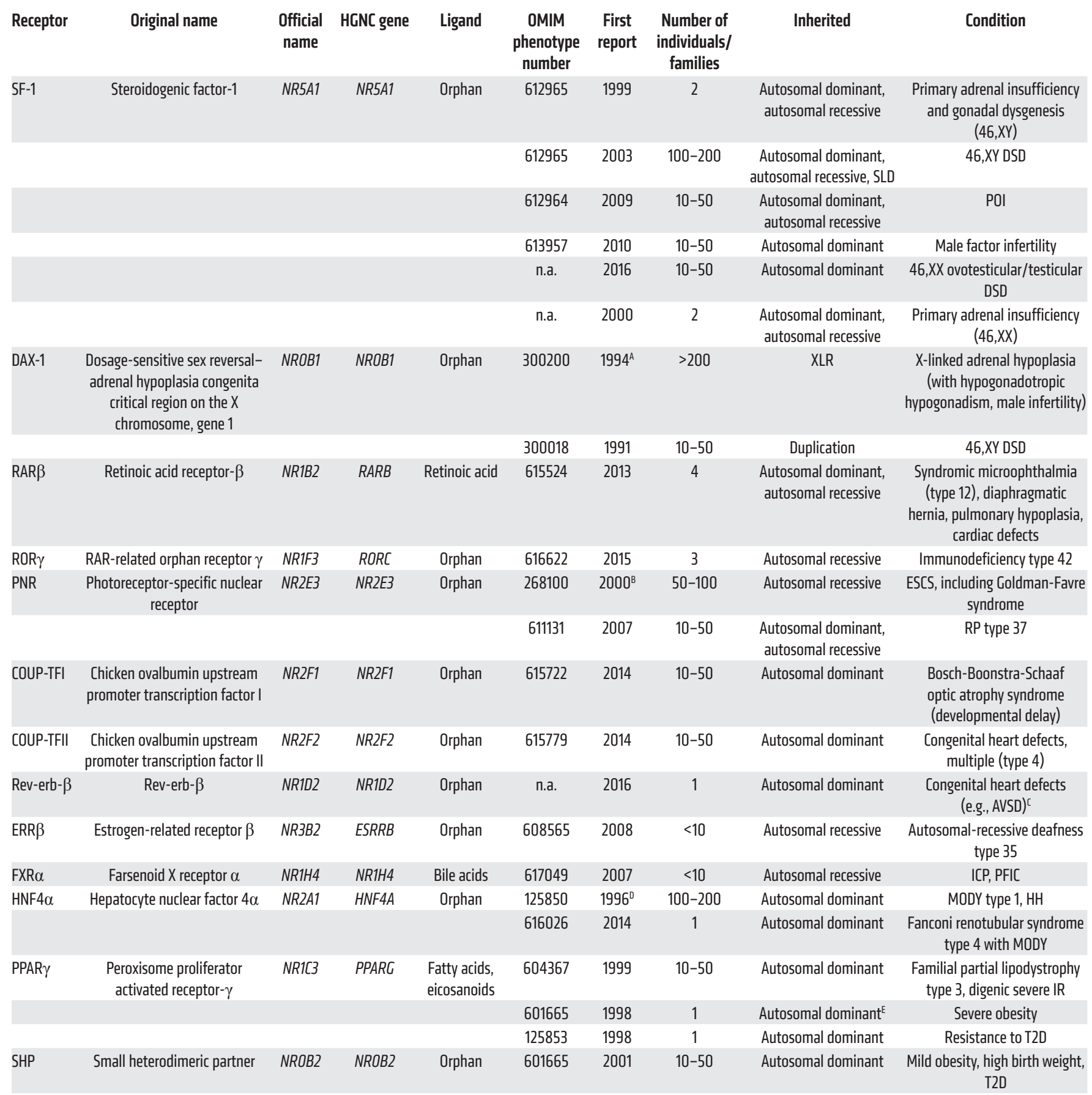

AX-linked AHC causing "cytomegalic" adrenal hypoplasia was first reported in 1948 and the X-linked basis identified in the 1970s, followed by reports of gene deletion syndromes involving chromosome Xp21 in the 1980s. ${ }^{8} E S C S$ was first described in 1990. In 1995 it was thought to be a disorder of photoreceptor determination and proliferation. ${ }^{\top}$ The association of mutations in Rev-erb- $\beta$ (NR1D2) with congenital heart defects is currently based on a single case report. ${ }^{D}$ MODY was first recognized in 1975 . Elnheritance patterns are tentative, especially when only one individual or family has been reported. n.a., not available; SLD, sex-linked dominant;. 


\section{Steroidogenic factor-1}

Steroidogenic factor-1 (SF-1, encoded by NR5A1) was identified following the search for a common regulator of steroidogenic enzyme transcription $(34,35)$. Complete deletion of Nr5a1 in the mouse resulted in adrenal agenesis, gonadal (testicular) dysgenesis with persistent Müllerian structures (in the uterus and upper vagina) in $\mathrm{XY}$ animals and variable defects in gonadotropin release, confirming SF-1 as a key player in adrenal and gonad biology (36). Subsequently, other metabolic features such as late-onset obesity and ventromedial hypothalamic abnormalities were reported $(37,38)$.

The first descriptions of pathogenic loss-of-function variants in NR5A1 in humans were published in 1999 and $2002(39,40)$. These reports included two 46,XY girls with testicular dysgenesis, Müllerian structures, and salt-losing primary adrenal insufficiency. The first child had a de novo heterozygous change (p. Gly35Glu) in the P-box region of the SF-1 DBD that affected binding to and transcriptional activation of target gene response elements (39). Functional studies suggested this was largely a gene dosage-dependent competitive effect, although partial dominant negativity was reported in some systems. The second child had a homozygous pathogenic change (p. Arg92Gln) affecting the A-box region of SF-1 DBD (40). SF-1 belongs to a small subgroup of NRs that bind to DNA as monomers rather than as homo- or heterodimers. The A-box region is involved in stabilizing monomeric binding through an interaction with the DNA minor groove. Thus, a heterozygous P-box change and homozygous A-box change may have similar phenotypes.

The past decade has seen great increases in the number of reported pathogenic changes in NR5A1 and also the spectrum of SF-1-associated conditions (41). More than 200 individuals and families are now described in the literature. Heterozygous loss-offunction variants in NR5A1 occur in approximately $15 \%$ of individuals with testicular dysgenesis and reduced androgen production, resulting in 46,XY differences in/disorders of sex development (DSDs) (42). Phenotypes can range from females with a $46, \mathrm{XY}$ karyotype to boys with penoscrotal hypospadias or undescended testes. Milder variants in NR5A1 can be associated with a small subset of male factor infertility, sometimes with progressive endocrine dysfunction (43). Variants in NR5A1 are also associated with primary ovarian insufficiency (POI) in $46, \mathrm{XX}$ women, although the age of onset and natural time course are highly variable (44). Although many variants occur de novo, around 30\% can be carried and maternally transmitted as a sex-limited dominant trait. Because multiple members of a family may have $46, \mathrm{XY}$ DSD with 46,XX females being at risk of POI, careful family history and counseling is important. Very rarely, mutations in NR5A1 can cause primary adrenal insufficiency in $46, \mathrm{XX}$ girls.

Although true gain-of-function variants in SF-1 have not been reported, recent observations suggest that recurrent, heterozygous missense changes in codon 92 (p.Arg92Trp, p.Arg92Gln) of NR5A1 are associated with ovotestes or testes in individuals with a 46,XX karyotype (45). Several individuals or families of diverse genetic ancestry have been reported. This particular amino acid change may interfere with expression of DAX-1 (dosage-sensitive sex reversal-adrenal hypoplasia congenita (AHC) critical region on the X chromosome, gene 1 ; see below) through WNT signaling in the developing gonad, but the exact mechanism that "switches" the ovary into a testis remains unclear (Figure 3D).

\section{DAX-1}

DAX-1 (encoded by NROB1) is an orphan NR that lacks the typical NR DBD but that has an aminoterminal region motif comprising three 66-67 amino acid tandem repeats. Similar to SF-1, DAX-1 plays a key role in adrenal and reproductive development.

DAX-1 disruption was first reported to cause X-linked AHC in $1994(46,47)$. Since then, more than 200 individuals or families have been reported to have pathogenic variants in NROB1 (41). The classic features in males include primary adrenal insufficiency in early infancy or childhood, delayed or arrested puberty due to disordered gonadotropin release, and impaired spermatogenesis.

Nonsense or frameshift variants in NROB1 occur throughout the gene, whereas pathogenic missense variants tend to cluster in key areas of the ligand-like binding domain in regions that form the hydrophobic core of the protein (48). Few missense changes in the aminoterminal repeat structure of DAX-1 have been reported. Partial loss-of-function missense variants can be associated with a milder phenotype of delayed onset adrenal insufficiency in early adulthood, or partial hypogonadotropic hypogonadism (49). Surprisingly, milder phenotypes can also occur due to stop gain variants at the start of the protein (p. Trp37*, p.Trp39*); this effect is likely due to re-initiation of translation of a truncated DAX-1 protein from a downstream methionine at codon 83 that remains partially functional (due to the repeat motif structure) and "rescues" the phenotype (50).

Although DAX-1-associated conditions are well established, the exact biological role of DAX-1 remains unclear. Many studies demonstrate that DAX-1 acts as a transcriptional repressor, potentially through a direct interaction with SF-1 (48). Indeed, duplication of the locus containing DAX-1 is associated with testicular dysgenesis, suggesting that it may act as an "anti-testis" gene. DAX-1 may play a role in regulating progenitor cell differentiation. Loss of DAX-1-dependent repression may result in premature differentiation of progenitor cells without appropriate expansion of cell numbers, ultimately resulting in tissue hypoplasia. Indeed, loss of DAX-1 can sometimes be associated with early puberty in humans, and transient adrenal hyperresponsiveness has been reported in Dax1 knockout mice (51). Whether these phenomena reflect the true biological basis of DAX-1 function is still unclear.

\section{Retinoic acid receptor- $\beta$}

Retinoic acid receptor- $\beta$ (RARB, encoded by NR1B2) is expressed in many tissues during development, and deletion of Nr1b2 in mice causes multiple defects (e.g., CNS, vision, hearing, musculoskeletal, cardiovascular, gastrointestinal, pulmonary, renal) and high lethality.

In 2013, the first pathogenic $R A R B$ variants were reported in patients with STRA6 mutation-negative syndromic microphthalmia and additional features such as pulmonary hypoplasia/agenesis, diaphragmatic hernia/eventration, anophthalmia/microphthalmia, and cardiac defects (PDAC syndrome). In one family, two siblings were found to be compound heterozygous for disruptive variants (p.Arg119*/p.Ile403SerfsTer15) (52). At least three other unrelated children with microphthalmia and one or more of these additional features have been found to carry de novo heterozygous changes affecting an arginine hotspot at codon 387 (e.g., p.Arg387Ser, p.Arg387Cys), potentially mediating a gain-offunction mechanism $(52,53)$. Taken together, these findings pro- 
vide support for retinoic acid pathways in human eye development and organogenesis. Indeed, NR1B2 is highly expressed in the human retina, unlike NR1B1 or NR1B3 (54).

\section{RAR-related orphan receptor $\gamma$}

RAR-related orphan receptor $\gamma$ (ROR $\gamma$, encoded by RORC [also known as NR1F3]) plays a key role in thymocyte development and function, including differentiation of the Th17 cell subset. Recently, homozygous pathogenic variants in $R O R C$, causing disruption of both the ROR- $\gamma$ and ROR- $\gamma$-t isoforms, have been reported in seven individuals from three unrelated consanguineous pedigrees with immunodeficiency (55). These families - from Palestine, Chile, and Saudi Arabia - have evidence of chronic mucocutaneous candidiasis (due to IL-17A and IL-17F deficiency) combined with susceptibility to mycobacterial disease and disseminated infections following Bacillus Calmette-Guérin vaccines. Patients also all had a small thymus.

\section{Photoreceptor-specific NR}

Photoreceptor-specific NR (PNR, encoded by NR2E3) is involved in retinal photoreceptor cell differentiation and degeneration, and its disruption results in retinal degeneration in the rd7 mouse. Pathogenic variants in NR2E3 cause enhanced S-cone syndrome (ESCS) (56), an inherited retinal disorder characterized by increased visual function of the minority $S$ (blue) cones and decreased L/M (red/green) cone and rod function. These findings likely represent increased S-cone proliferation at the expense of other cell types during cell fate determination. Patients typically develop night blindness and evidence of retinitis pigmentosa (RP). Autopsy studies have shown absence of rods and retinal disorganization and degeneration (57).

Among pathogenic variants in NR2E3 reported to cause ESCS, homozygous p.Arg311Gln variants are most common and represent a hotspot for disease among the Crypto-Jewish population in Portugal (58). The same change is also associated with Golgmann-Favre syndrome, a more severe form of ESCS (55). Variants in NR2E3 are also found in autosomal-recessive and -dominant forms of RP $(59,60)$. Approximately $3 \%$ of dominantly inherited $\mathrm{RP}$ is due to a heterozygous PNR mutation (p.Gly56Arg) in the first zinc finger of the DBD, exhibiting dominant-negative activity (60, $61)$. Other variants cause altered cellular localization or homo- or hetero-dimerization with TLX/NR2E1 and RXR $\alpha / \mathrm{NR} 2 \mathrm{C} 1$ (62, 63). Another NR, Rev-erb- $\alpha$ /NR1D1, has been used to potentially "rescue" disease progression in the rd7 mouse (64).

\section{Chicken ovalbumin upstream promoter transcription factor I (NR2F1)}

Chicken ovalbumin upstream promoter transcription factor I (COUP-TFI) is widely expressed in many tissues. It is strongly expressed in the brain and peripheral nervous system and has a potential role in regionalization of the neocortex and axonal projection. In humans, NR2F1 haploinsufficiency and de novo heterozygous mutations in NR2F1 have been reported in patients with Bosch-Boonstra-Schaaf optic atrophy syndrome $(65,66)$. Additional characteristics include developmental delay and variable, nonspecific facial features. Most missense mutations (such as p.Arg112Lys, p.Ser113Arg, and p.Arg115Pro) cluster in the DBD and may be associated with a more severe phenotype $(66,67)$. Other features reported recently include hypotonia, oromotor dysfunction, thinning of the corpus callosum, seizures, autism spectrum disorder, and hearing impairment (67).

\section{COUP-TFII}

COUP-TFII (encoded by NR2F2) plays a role in angiogenesis, vascular remodeling, and heart development as well as in more widespread regulation of cell fate during embryonic development. Recently, heterozygous variants in NR2F2 have been reported in patients with a range of congenital cardiac disease phenotypes (68). In one family, a 3-bp duplication in NR2F2 segregated with multiple cardiac defects (i.e., atrioventricular septal defect [AVSD], aortic stenosis/VSD, and tetralogy of Fallot), whereas other heterozygous missense mutations or deletions of $N R 2 F 2$ have been associated with AVSD, hypoplastic left heart syndrome, or aortic coarctation (68). Congenital diaphragmatic hernia may be an association in mice and humans (69).

\section{Rev-erb- $\beta$}

Rev-erb- $\beta$ (encoded by NR1D2) has several proposed actions including being a potential repressor of gene transcription. Recently, a de novo heterozygous mutation in NR1D2 was found in one individual with congenital heart disease (AVSD) (70). This variant (p.Arg175Trp) affects binding to the DNA minor groove and impairs transcriptional repression (70). Detailed analysis of $\mathrm{Nr} 1 \mathrm{~d}^{-/-}$mice indicated a similar phenotype (70). As this is a very recent observation, the true contribution of Rev-erb- $\beta$ to developmental heart defects is not yet known.

\section{Estrogen-related receptor $\beta$ (NR3B2)}

Estrogen-related receptor $\beta$ (ERR $\beta$, encoded by NR3B2) has structural homology to the ERs and binds ER response elements but is not activated by estrogens. ERR $\beta$ plays a role in placental development and is expressed in several tissues such as the inner ear during development and postnatal life (71). Homozygous disruption of ESRRB was first reported in a large consanguineous Turkish family with autosomal-recessive nonsyndromic hearing loss (type 35) (72). Homozygous point mutations in the DBD and, more often, in the "ligand"-binding domain of ERR $\beta$ have also been reported as a rare cause of nonsyndromic hearing loss, often in consanguineous families (72). A potential link between disruption of ESRRB and dental caries has also been proposed (73).

\section{Farnesoid $X$ receptor}

Farnesoid X receptor (FXR, encoded by NR1H4), a bile acidactivated NR, is a key mediator of bile acid homeostasis, regulating target genes that mediate hepatic export (e.g., bile salt export pump [ABCB11], multidrug resistance protein 3 [ABCB4]), biosynthesis (e.g., $C Y P 7 A$ ), or enterohepatic circulation (e.g., NTCP, $I B A B P)$ of bile acids, limiting their intrinsic hepatocellular toxicity.

Four different heterozygous $N R 1 H 4$ variants $(-1 G>T$, p.Met1Val, p.Trp80Arg, and p.Met173Thr) that reduce its expression or transcriptional activity were identified by screening 92 women with intrahepatic cholestasis of pregnancy (ICP), a disorder characterized by late gestational pruritus and abnormal maternal and fetal liver function, predisposing to fetal distress and prematurity 
(74). The heterozygous $-1 \mathrm{G}>\mathrm{T}$ variant was subsequently identified in an unrelated ICP case (75).

Progressive familial intrahepatic cholestasis (PFIC) comprises three subtypes known to be associated with mutations in transport proteins (PFIC-1, encoded by ATP8B1; PFIC-2, encoded by $A B C B 11 / B S E P$; and PFIC-3, encoded by $A B C B 4)$, but $30 \%$ of cases are idiopathic. FXR variants have recently been identified in four children with severe neonatal cholestasis that progressed to liver failure that was terminal or required transplantation. A homozygous premature stop mutation (p.Arg176*) abrogating DNA binding and function was identified in one family, and compound heterozygosity for an in-frame DBD insertion (pTyr139_Asn140insLys) plus a 31-kb deletion encompassing the first two coding exons of NR1H4 was identified in a second family. Similar to previous PFIC cases with defective bile salt export pump (BSEP, a known FXR target), cholestasis was associated with low/normal $\gamma$-glutamyl transferase levels and reduced BSEP expression. Severe vitamin K-independent coagulopathy, attributed to reduced FXR-dependent clotting factor levels and reduced circulating levels of other FXR-dependent hormones and metabolites, may represent other distinctive, diagnostically useful biomarkers (76).

\section{Hepatocyte nuclear factor $4 \alpha$}

Hepatocyte nuclear factor $4 \alpha$ (HNF $4 \alpha$, encoded by NR2A1) controls gene expression in the liver (approximately $40 \%$ of actively transcribed genes) and pancreas ( $11 \%$ of islet cell genes) and regulates pathways of hepatic gluconeogenesis and pancreatic insulin secretion (77).

Maturity-onset diabetes of the young (MODY), usually defined as diabetes mellitus (diagnosed before age 25 years) with negative islet cell autoantibodies, is most commonly (in about $50 \%$ of cases) due to mutations in HNF1 $\alpha$ (MODY type 3), a homeobox family transcription factor, with $H N F 4 A$ variants accounting for a further $10 \%$ of cases (MODY type 1). Approximately 100 different heterozygous mutations (58\% missense, $20 \%$ frameshift or premature stop, $5 \%$ splice site) localizing to HNF4A coding exons have been recorded in this dominantly inherited disorder; a further $5 \%$ of variants localize to the pancreatic P2 promoter region of $H N F 4 A$, disrupting known tissue-specific transcription factor binding sites (77). Some HNF4 $\alpha$ mutations, even those located outside the canonical DBD, compromise a protein interface in the HNF $4 \alpha$ homodimer bound to DNA (78), with other variants disrupting transactivation, nuclear localization, or protein stability. Due to the large number of $\mathrm{HNF} 4 \alpha$-regulated target genes in liver and pancreas, it has been postulated that haploinsufficiency, with loss of even a fraction of functional receptor homodimers, reduces pancreatic glucose-dependent insulin secretion, mediating MODY (79).

In addition to a young age of diagnosis and family history of early-onset diabetes, reduced serum ApoA2 (known to be HNF4 $\alpha$ regulated) and triglyceride levels and exquisite sensitivity to sulfonylurea drug therapy may be useful markers of HNF $4 \alpha$ MODY (80). HNF4A mutation carriage is also associated with excess insulin secretion, resulting in macrosomia and neonatal hyperinsulinemic hypoglycemia $(\mathrm{HH})$ in up to $50 \%$ of babies; the latter mandates neonatal surveillance of affected pregnancies because $\mathrm{HH}$ can be either mild and transient or more severe, requiring treatment with diazoxide (81). In addition to neonatal hyperin- sulinism and macrosomia, renal proximal tubulopathy (Fanconi syndrome) with elevated urinary calcium, phosphate, and oxalate causing nephrocalcinosis has been recorded in patients with a specific HNF4 $\alpha$ mutation (p.Arg76Trp) (82).

GWAS do show linkage of common variants around the HNF4A locus with T2D; a rare variant (p.Thr130Ile) in HNF4A confers a modest (1.2-fold) risk of T2D and is positively associated with HDL cholesterol levels (77).

\section{PPAR $\gamma$}

PPAR $\gamma$ (encoded by NR1C3) is essential for adipocyte differentiation but also regulates target genes that mediate triglyceride hydrolysis and fatty acid and glycerol uptake, together with genes involved in fatty acid re-esterification and lipid storage (83). Heterozygous, missense PPARG mutations (p. Pro467Leu, Val$290 \mathrm{Met}$ ), impairing its ligand-dependent transcriptional activity, were first identified in patients with severe insulin resistance (IR) and early-onset T2D (84); subsequently, the phenotype was recognized to encompass a distinctive pattern of partial lipodystrophy. Additional features, such as hepatic steatosis and dyslipidemia, likely reflect an impaired ability to buffer dietary lipid load, with tissue lipotoxicity mediating IR. The resulting hyperinsulinemia mediates polycystic ovarian dysfunction and acanthosis nigricans. Hypertension that occurs independent of diabetic comorbidities is also a feature, suggesting a direct role for PPAR $\gamma$ in control of vascular tone (83).

Rare heterozygous PPARG variants associated with lipodystrophic IR localize to the LBD or DBD, disrupting either DNA binding or ligand-dependent transcription activation functions. Additionally, mutant receptors inhibit function of their wild-type counterparts in a dominant-negative manner (85). In a large, digenic kindred, PPAR $\gamma$ haploinsufficiency alone did not mediate IR, but acted in concert with a PPP1R3A mutation that affects muscle glycogen synthesis (86). Whole exome sequencing of around 9,000 individuals with T2D identified nine functionally deleterious, rare PPARG variants that confer substantial disease risk; however, it could not be ascertained whether adipose mass was reduced in these subjects (87). A common PPARG variant (p.Pro12Ala) that occurs with varying frequency (2\% to $18 \%$ ) in different ethnic groups is associated with a reduction in T2D risk (odds ratio 0.86). Conversely, the Pro12 allele is present in $80 \%$ of humans and can increase population T2D risk by up to $25 \%$ (85). Reduced target gene activation and induction of adipogenesis by the Ala12 PPAR $\gamma$ variant may lower adipose mass and improve insulin sensitivity in carriers, being the basis of its protective effect (88). A rare variant (p.Pro113Gln) in the PPAR $\gamma$ aminoterminal domain that exhibits gain of transcriptional function has been documented in four obese but paradoxically diabetic German subjects, but this or similar variants have not been found in other obese populations, suggesting a strong founder effect (85).

\section{Small heterodimeric partner}

Small heterodimer partner (SHP, encoded by NROB2) is an atypical orphan NR that has a ligand-like binding domain with sequence homology to other NRs but with a truncated aminoterminal region that lacks a true DBD. Heterozygous NROB2 variants with a diminished ability to inhibit HNF $4 \alpha$ function were reported in 7\% of Jap- 
anese patients with early-onset T2D, mild/moderate obesity, and increased birth weight (89). A separate study documented lossof-function NROB2 variants in 2.4\% (19/805) of Japanese people with T2D, but also found these variants in $0.8 \%$ (6/752) of controls without diabetes (90). In contrast, studies in different populations have not consistently found such high enrichment for rare SHP variants in cohorts with obesity or diabetes (81-94).

\section{Conclusions}

The identification of naturally occurring NR mutations over the last 30 years has provided insights into their structure and function, but there are still many NRs for which an associated disorder has not yet been discovered. Looking to the future, exome or genome sequencing may uncover an association of NR gene variants with unexpected phenotypes or disorders not readily predicted from their known roles in physiologic or developmental processes. In other situations, the phenotype might be subtle or even embryonic lethal. These technologies will also identify genetic variants whose functional consequences are uncertain, emphasizing the need to develop relevant, high-throughput assays of variant NR function that can accurately predict their pathogenic significance, as has been described recently for PPARG (95).

With disorders of many classical NRs associated with changes in hormone levels linked to their cognate ligands, it is likely that defects in orphan receptors are also accompanied by distinctive changes in circulating metabolites or proteins. Metabolomic or proteomic profiling of case cohorts with defined NR gene defects may discern characteristic biochemical signatures, enabling bet- ter diagnosis of associated disorders or providing clues to the identification of unknown orphan receptor ligands.

A subset of individuals with typical clinical or biochemical features suggestive of disordered NR action do not have mutations in NR proteins, and it is possible that variants in non-coding regions of the genome affecting function of enhancer regions or involving epigenetic modification of chromatin or non-coding RNAs account for such cases. Alternatively, it is possible that defects in genes encoding NR cofactor proteins may be associated with such phenotypes. With our increasing knowledge of the human genome and application of high-throughput technologies to genome analysis and small-molecule screening, the next 30 years are likely to be an equally exciting time for human NR research.

\section{Acknowledgments}

Our research is supported by funding from the Wellcome Trust (Investigator Award 095564/Z/11/Z to KC; Senior Research Fellowship in Clinical Science 098513/Z/12/Z to JCA; Investigator Award 100237/Z/12/Z to JS), the National Institute for Health Research Biomedical Research Centre at Cambridge (to KC), and Great Ormond St Hospital for Children NHS Foundation Trust and University College London (to JCA). JS is a Royal Society Wolfson Research Merit Award Holder.

Address correspondence to: V. Krishna K. Chatterjee, University of Cambridge, Metabolic Research Laboratories, Institute of Metabolic Science, Level 4, Box 289, Addenbrooke's Hospital, Cambridge, CB2 OQQ. Phone: 44.1223.336842; E-mail: kkc1@medschl.cam.ac.uk.
1. Gurnell M, Visser TJ, Beck-Peccoz P, Chatterjee VK. Resistance to thyroid hormone. In: Jameson JL, DeGroot LJ, eds. Endocrinology. 7th ed. 2015:1648-1665.

2. Takeda K, Sakurai A, DeGroot LJ, Refetoff S. Recessive inheritance of thyroid hormone resistance caused by complete deletion of the protein-coding region of the thyroid hormone receptor-beta gene. JClin Endocrinol Metab. 1992;74(1):49-55.

3. Ferrara AM, Onigata K, Ercan O, Woodhead $\mathrm{H}$, Weiss RE, Refetoff S. Homozygous thyroid hormone receptor $\beta$-gene mutations in resistance to thyroid hormone: three new cases and review of the literature. JClin Endocrinol Metab. 2012;97(4):1328-1336.

4. Bochukova $\mathrm{E}$, et al. A dominant negative mutation in the thyroid hormone receptor $\alpha$ gene. N Engl JMed. 2012;366(3):243-249.

5. Moran C, Chatterjee VK. Resistance to thyroid hormone due to defective thyroid receptor $\alpha$. Best Pract Res Clin Endocrinol Metab. 2015;29(4):647-657.

6. Moran C, et al. Resistance to thyroid hormone caused by a mutation in thyroid hormone receptor (TR) $\alpha 1$ and TR $\alpha 2$ : clinical, biochemical, and genetic analyses of three related patients. Lancet Diabetes Endocrinol. 2014;2(8):619-626.

7. Feldman D, J Malloy J. Mutations in the vitamin $\mathrm{D}$ receptor and hereditary vitamin D-resistant rickets. Bonekey Rep. 2014;3:510.

8. Malloy PJ, Zhou Y, Wang J, Hiort O, Feldman D.
Hereditary vitamin D-resistant rickets (HVDRR) owing to a heterozygous mutation in the vitamin D receptor. J Bone Miner Res. 2011;26(11):2710-2718.

9. Nakabayashi M, et al. Crystal structures of hereditary vitamin D-resistant rickets-associated vitamin D receptor mutants R270L and W282R bound to 1,25-dihydroxyvitamin D3 and synthetic ligands. JMed Chem. 2013;56(17):6745-6760.

10. Malloy PJ, Feldman D. The role of vitamin D receptor mutations in the development of alopecia. Mol Cell Endocrinol. 2011;347(1-2):90-96.

11. Hurley DM, et al. Point mutation causing a single amino acid substitution in the hormone binding domain of the glucocorticoid receptor in familial glucocorticoid resistance. J Clin Invest. 1991;87(2):680-686.

12. Nicolaides NC, Charmandari E. Chrousos syndrome: from molecular pathogenesis to therapeutic management. Eur J Clin Invest. 2015;45(5):504-514.

13. Kino T, Stauber RH, Resau JH, Pavlakis GN, Chrousos GP. Pathologic human GR mutant has a transdominant negative effect on the wild-type GR by inhibiting its translocation into the nucleus: importance of the ligand-binding domain for intracellular GR trafficking. J Clin Endocrinol Metab. 2001;86(11):5600-5608.

14. Charmandari E, Kino T, Souvatzoglou E, Vottero A, Bhattacharyya N, Chrousos GP. Natural glucocorticoid receptor mutants causing generalized glucocorticoid resistance: molecular genotype, genetic transmission, and clinical phenotype. J Clin Endocrinol Metab. 2004;89(4):1939-1949.

15. Charmandari E, et al. A novel point mutation in the amino terminal domain of the human glucocorticoid receptor (hGR) gene enhancing hGR-mediated gene expression. J Clin Endocrinol Metab. 2008;93(12):4963-4968.

16. Geller DS, et al. Mutations in the mineralocorticoid receptor gene cause autosomal dominant pseudohypoaldosteronism type I. Nat Genet. 1998;19(3):279-281.

17. Pujo L, et al. Mineralocorticoid receptor mutations are the principal cause of renal type 1 pseudohypoaldosteronism. Hum Mutat. 2007;28(1):33-40.

18. Riepe FG, et al. Elucidating the underlying molecular pathogenesis of NR3C2 mutants causing autosomal dominant pseudohypoaldosteronism type 1. J Clin Endocrinol Metab. 2006;91(11):4552-4561.

19. Fernandes-Rosa FL, et al. Mineralocorticoid receptor mutations differentially affect individual gene expression profiles in pseudohypoaldosteronism type 1. J Clin Endocrinol Metab. 2011;96(3):E519-E527.

20. Geller DS, et al. Activating mineralocorticoid receptor mutation in hypertension exacerbated by pregnancy. Science. 2000;289(5476):119-123.

21. Smith EP, et al. Estrogen resistance caused by a mutation in the estrogen-receptor gene in a man. N Engl JMed. 1994;331(16):1056-1061. 
22. Smith EP, et al. Impact on bone of an estrogen receptor-alpha gene loss of function mutation. JClin Endocrinol Metab. 2008;93(8):3088-3096.

23. Quaynor SD, et al. Delayed puberty and estrogen resistance in a woman with estrogen receptor $\alpha$ variant. N Engl JMed. 2013;369(2):164-171.

24. Bernard V, et al. Familial multiplicity of estrogen insensitivity associated with a loss-of-function ESR1 mutation. J Clin Endocrinol Metab. 2017;102(1):93-99.

25. Lubahn DB, et al. Sequence of the intron/exon junctions of the coding region of the human androgen receptor gene and identification of a point mutation in a family with complete androgen insensitivity. Proc Natl Acad Sci U S A. 1989;86(23):9534-9538.

26. Hughes IA, Davies JD, Bunch TI, Pasterski V, Mastroyannopoulou K, MacDougall J. Androgen insensitivity syndrome. Lancet. 2012;380(9851):1419-1428.

27. McPhaul MJ, Marcelli M, Tilley WD, Griffin JE, Isidro-Gutierrez RF, Wilson JD. Molecular basis of androgen resistance in a family with a qualitative abnormality of the androgen receptor and responsive to high-dose androgen therapy. J Clin Invest. 1991;87(4):1413-1421.

28. Ferlin A, et al. Male infertility and androgen receptor gene mutations: clinical features and identification of seven novel mutations. Clin Endocrinol (Oxf). 2006;65(5):606-610.

29. Gottlieb B, Beitel LK, Nadarajah A, Paliouras $\mathrm{M}$, Trifiro $\mathrm{M}$. The androgen receptor gene mutations database: 2012 update. Hum Mutat. 2012;33(5):887-894.

30. Jewish General Hospital. The Androgen Receptor Gene Mutations Database World Wide Web Server. McGill University Web site. http://androgendb.mcgill.ca/. Updated September 10, 2014. Accessed February 23, 2017.

31. Hornig NC, et al. Identification of an AR mutationnegative class of androgen insensitivity by determining endogenous AR activity. J Clin Endocrinol Metab. 2016;101(11):4468-4477.

32. La Spada AR, Wilson EM, Lubahn DB, Harding $\mathrm{AE}$, Fischbeck KH. Androgen receptor gene mutations in X-linked spinal and bulbar muscular atrophy. Nature. 1991;352(6330):77-79.

33. La Spada A. Spinal and bulbar muscular atrophy. In: Pagon RA, et al., eds. GeneReviews. Seattle, Washington, USA: University of Washington, Seattle; 1993-2017.

34. Rice DA, Mouw AR, Bogerd AM, Parker KL. A shared promoter element regulates the expression of three steroidogenic enzymes. Mol Endocrinol. 1991;5(10):1552-1561.

35. Morohashi K, Honda S, Inomata Y, Handa $\mathrm{H}$, Omura T. A common trans-acting factor, Ad4-binding protein, to the promoters of steroidogenic P-450s. J Biol Chem. 1992;267(25):17913-17919.

36. Luo X, Ikeda Y, Parker KL. A cell-specific nuclear receptor is essential for adrenal and gonadal development and sexual differentiation. Cell. 1994;77(4):481-490.

37. Majdic G, et al. Knockout mice lacking steroidogenic factor 1 are a novel genetic model of hypothalamic obesity. Endocrinology. 2002;143(2):607-614.
38. Shinoda K, et al. Developmental defects of the ventromedial hypothalamic nucleus and pituitary gonadotroph in the Ftz-F1 disrupted mice. Dev Dyn. 1995;204(1):22-29.

39. Achermann JC, Ito M, Ito M, Hindmarsh PC, Jameson JL. A mutation in the gene encoding steroidogenic factor- 1 causes XY sex reversal and adrenal failure in humans. Nat Genet. 1999;22(2):125-126.

40. Achermann JC, et al. Gonadal determination and adrenal development are regulated by the orphan nuclear receptor steroidogenic factor- 1 , in a dose-dependent manner. J Clin Endocrinol Metab. 2002;87(4):1829-1833

41. Suntharalingham JP, Buonocore F, Duncan AJ, Achermann JC. DAX-1 (NROB1) and steroidogenic factor-1 (SF-1, NR5A1) in human disease. Best Pract Res Clin Endocrinol Metab. 2015;29(4):607-619.

42. Lin L, et al. Heterozygous missense mutations in steroidogenic factor 1 (SF1/Ad4BP, NR5A1) are associated with 46,XY disorders of sex development with normal adrenal function. J Clin Endocrinol Metab. 2007;92(3):991-999.

43. Bashamboo A, et al. Human male infertility associated with mutations in NR5A1 encoding steroidogenic factor 1. Am J Hum Genet. 2010;87(4):505-512.

44. Lourenço D, et al. Mutations in NR5A1 associated with ovarian insufficiency. $N$ EnglJ Med. 2009;360(12):1200-1210.

45. Bashamboo A, et al. A recurrent p.Arg92Trp variant in steroidogenic factor-1 (NR5A1) can act as a molecular switch in human sex development. Hum Mol Genet. 2016;25(16):3446-3453.

46. Zanaria E, et al. An unusual member of the nuclear hormone receptor superfamily responsible for $\mathrm{X}$-linked adrenal hypoplasia congenita. Nature. 1994;372(6507):635-641.

47. Muscatelli F, et al. Mutations in the DAX-1 gene give rise to both $\mathrm{X}$-linked adrenal hypoplasia congenita and hypogonadotropic hypogonadism. Nature. 1994;372(6507):672-676.

48. Achermann JC, et al. Missense mutations cluster within the carboxyl-terminal region of DAX-1 and impair transcriptional repression. J Clin Endocrinol Metab. 2001;86(7):3171-3175.

49. Tabarin A, et al. A novel mutation in DAX1 causes delayed-onset adrenal insufficiency and incomplete hypogonadotropic hypogonadism. J Clin Invest. 2000;105(3):321-328.

50. Ozisik G, et al. An alternate translation initiation site circumvents an amino-terminal DAX1 nonsense mutation leading to a mild form of X-linked adrenal hypoplasia congenita. J Clin Endocrinol Metab. 2003;88(1):417-423.

51. Scheys JO, Heaton JH, Hammer GD. Evidence of adrenal failure in aging Dax1-deficient mice. Endocrinology. 2011;152(9):3430-3439.

52. Srour M, et al. Recessive and dominant mutations in retinoic acid receptor beta in cases with microphthalmia and diaphragmatic hernia. Am J Hum Genet. 2013;93(4):765-772.

53. Slavotinek AM, et al. Exome sequencing in 32 patients with anophthalmia/microphthalmia and developmental eye defects. Clin Genet. 2015;88(5):468-473.

54. The Human Protein Atlas. FANTHOM5 dataset. RARB Web site. http://www.proteinatlas.org/
ENSG00000077092-RARB/tissue. Accessed

February 23, 2017.

55. Okada S, et al. IMMUNODEFICIENCIES. Impairment of immunity to Candida and Mycobacterium in humans with bi-allelic RORC mutations. Science. 2015;349(6248):606-613.

56. Haider NB, et al. Mutation of a nuclear receptor gene, NR2E3, causes enhanced S cone syndrome, a disorder of retinal cell fate. Nat Genet. 2000;24(2):127-131.

57. Milam AH, et al. The nuclear receptor NR2E3 plays a role in human retinal photoreceptor differentiation and degeneration. Proc Natl Acad Sci U S A. 2002;99(1):473-478.

58. Gerber S, et al. The photoreceptor cell-specific nuclear receptor gene (PNR) accounts for retinitis pigmentosa in the Crypto-Jews from Portugal (Marranos), survivors from the Spanish Inquisition. Hum Genet. 2000;107(3):276-284.

59. Bernal S, et al. Analysis of the involvement of the NR2E3 gene in autosomal recessive retinal dystrophies. Clin Genet. 2008;73(4):360-366.

60. Coppieters F, et al. Recurrent mutation in the first zinc finger of the orphan nuclear receptor NR2E3 causes autosomal dominant retinitis pigmentosa. Am J Hum Genet. 2007;81(1):147-157.

61. Blanco-Kelly F, et al. Dominant retinitis pigmentosa, p.Gly56Arg mutation in NR2E3: phenotype in a large cohort of 24 cases. PLoS One. 2016;11(2):e0149473.

62. Kanda A, Swaroop A. A comprehensive analysis of sequence variants and putative disease-causing mutations in photoreceptor-specific nuclear receptor NR2E3. Mol Vis. 2009;15:2174-2184.

63. von Alpen D, et al. Differential dimerization of variants linked to enhanced S-cone sensitivity syndrome (ESCS) located in the NR2E3 ligand-binding domain. Hum Mutat. 2015;36(6):599-610.

64. Cruz NM, et al. Modifier genes as therapeutics: the nuclear hormone receptor Rev Erb alpha (Nr1d1) rescues Nr2e3 associated retinal disease. PLoS One. 2014;9(1):e87942.

65. Al-Kateb H, Shimony JS, Vineyard M, Manwaring L, Kulkarni S, Shinawi M. NR2F1 haploinsufficiency is associated with optic atrophy, dysmorphism and global developmental delay. Am J Med Genet A. 2013;161A(2):377-381.

66. Bosch DG, et al. NR2F1 mutations cause optic atrophy with intellectual disability. Am J Hum Genet. 2014;94(2):303-309.

67. Chen CA, et al. The expanding clinical phenotype of Bosch-Boonstra-Schaaf optic atrophy syndrome: 20 new cases and possible genotype-phenotype correlations. Genet Med. 2016;18(11):1143-1150.

68. Al Turki S, et al. Rare variants in NR2F2 cause congenital heart defects in humans. Am J Hum Genet. 2014;94(4):574-585.

69. High FA, Bhayani P, Wilson JM, Bult CJ, Donahoe PK, Longoni M. De novo frameshift mutation in COUP-TFII (NR2F2) in human congenital diaphragmatic hernia. Am JMed Genet A. 2016;170(9):2457-2461.

70. Priest JR, et al. De novo and rare variants at multiple loci support the oligogenic origins of atrioventricular septal heart defects. PLoS Genet. 2016;12(4):e1005963.

71. Divekar SD, Tiek DM, Fernandez A, Riggins RB. 
Estrogen-related receptor $\beta(\mathrm{ERR} \beta)$ - renaissance receptor or receptor renaissance? $\mathrm{Nucl}$ Recept Signal. 2016;14:e002.

72. Collin RW, et al. Mutations of ESRRB encoding estrogen-related receptor beta cause autosomalrecessive nonsyndromic hearing impairment DFNB35. Am J Hum Genet. 2008;82(1):125-138.

73. Weber ML, et al. Role of estrogen related receptor beta (ESRRB) in DFN35B hearing impairment and dental decay. BMC Med Genet. 2014;15:81.

74. Van Mil SW, et al. Functional variants of the central bile acid sensor FXR identified in intrahepatic cholestasis of pregnancy. Gastroenterology. 2007;133(2):507-516.

75. Davit-Spraul A, Gonzales E, Jacquemin E. NR1H4 analysis in patients with progressive familial intrahepatic cholestasis, drug-induced cholestasis or intrahepatic cholestasis of pregnancy unrelated to ATP8B1, ABCB11 and ABCB4 mutations. Clin Res Hepatol Gastroenterol. 2012;36(6):569-573.

76. Gomez-Ospina N, et al. Mutations in the nuclear bile acid receptor FXR cause progressive familial intrahepatic cholestasis. Nat Commun. 2016;7:10713.

77. Colclough K, Bellanne-Chantelot C, SaintMartin C, Flanagan SE, Ellard S. Mutations in the genes encoding the transcription factors hepatocyte nuclear factor 1 alpha and 4 alpha in maturity-onset diabetes of the young and hyperinsulinemic hypoglycemia. Hum Mutat. 2013;34(5):669-685.

78. Chandra V, Huang P, Potluri N, Wu D, Kim Y, Rastinejad F. Multidomain integration in the structure of the HNF- $4 \alpha$ nuclear receptor complex. Nature. 2013;495(7441):394-398.

79. Shih DQ, Dansky HM, Fleisher M, Assmann G,
Fajans SS, Stoffel M. Genotype/phenotype relationships in HNF-4alpha/MODY1: haploinsufficiency is associated with reduced apolipoprotein (AII), apolipoprotein (CIII), lipoprotein(a), and triglyceride levels. Diabetes. 2000;49(5):832-837.

80. Pearson ER, et al. Molecular genetics and phenotypic characteristics of MODY caused by hepatocyte nuclear factor 4alpha mutations in a large European collection. Diabetologia. 2005;48(5):878-885.

81. Pearson ER, et al. Macrosomia and hyperinsulinaemic hypoglycaemia in patients with heterozygous mutations in the HNF4A gene. PLoS Med. 2007;4(4):e118.

82. Hamilton AJ, et al. The HNF4A R76W mutation causes atypical dominant Fanconi syndrome in addition to a $\beta$ cell phenotype. JMed Genet. 2014;51(3):165-169.

83. Semple RK, Chatterjee VK, O'Rahilly S. PPAR $\gamma$ and human metabolic disease. J Clin Invest. 2006;116(3):581-589.

84. Barroso I, et al. Dominant negative mutations in human PPARgamma associated with severe insulin resistance, diabetes mellitus and hypertension. Nature. 1999;402(6764):880-883.

85. Jeninga EH, Gurnell M, Kalkhoven E. Functional implications of genetic variation in human PPARgamma. Trends Endocrinol Metab. 2009;20(8):380-387.

86. Savage DB, et al. Digenic inheritance of severe insulin resistance in a human pedigree. $\mathrm{Nat}$ Genet. 2002;31(4):379-384.

87. Majithia AR, et al. Rare variants in PPARG with decreased activity in adipocyte differentiation are associated with increased risk of type 2 diabetes.
Proc Natl Acad Sci US A. 2014;111(36):13127-13132.

88. Gouda HN, Sagoo GS, Harding AH, Yates

J, Sandhu MS, Higgins JP. The association between the peroxisome proliferator-activated receptor-gamma2 (PPARG2) Pro12Ala gene variant and type 2 diabetes mellitus: a HuGE review and meta-analysis. Am J Epidemiol. 2010;171(6):645-655.

89. Nishigori H, et al. Mutations in the small heterodimer partner gene are associated with mild obesity in Japanese subjects. Proc Natl Acad Sci U S A. 2001;98(2):575-580.

90. Enya M, et al. Mutations in the small heterodimer partner gene increase morbidity risk in Japanese type 2 diabetes patients. Hum Mutat. 2008;29(11):E271-E277.

91. Mitchell SM, et al. Genetic variation in the small heterodimer partner gene and young-onset type 2 diabetes, obesity, and birth weight in U.K. subjects. Diabetes. 2003;52(5):1276-1279.

92. Hung CC, et al. Contribution of variants in the small heterodimer partner gene to birthweight, adiposity, and insulin levels: mutational analysis and association studies in multiple populations. Diabetes. 2003;52(5):1288-1291.

93. Echwald SM, et al. Mutation analysis of NROB2 among 1545 Danish men identifies a novel c. $278 \mathrm{G}>$ A (p.G93D) variant with reduced functional activity. Hum Mutat. 2004;24(5):381-387.

94. Ahituv N, et al. Medical sequencing at the extremes of human body mass. Am J Hum Genet 2007;80(4):779-791.

95. Majithia AR, et al. Prospective functional classification of all possible missense variants in PPARG. Nat Genet. 2016;48(12):1570-1575. 